\title{
Levodopa's awakening effect on patients with Parkinsonism
}

\author{
GAYLE G. MARSH, CHARLES M. MARKHAM, AND ROBERT ANSEL \\ From the Departments of Neurology and Psychiatry, School of Medicine, University of California, Los Angeles \\ U.S.A.
}

SUMMARY The effects of levodopa on tests measuring auditory and visual perception, auditory, and visual short-term memory, verbal learning, and on attention and concentration were studied in 29 patients with Parkinsonism. Thirty-two control subjects matched with the Parkinsonism patients on age, educational level, and verbal IQ were administered the same tests to control for practice effects. Significant improvement occurred for the Parkinsonism patients in verbal learning (an intermediate memory test) and in auditory perception. These improvements were unrelated to changes in anticholinergic medications, increases in alertness or concentration, lessening of depression, or improved motor ability or control. There was no test evidence of levodopa improving visual perception, short-term auditory or visual memory, alertness or concentration. Thus, there is no objective test evidence for levodopa producing a generalized awakening or an alerting effect in Parkinsonism patients who are intellectually alert and well-orientated. Interpretation of the test findings suggests a specific awakening effect, that of improvement in intermediate memory but not in short-term memory. Overall, the Parkinsonism group scored below the control group on all tests, suggesting that cognitive impairment accompanies Parkinson's disease even in patients who are intellectually intact and well oriented.

During clinical evaluations of the initial 70 Parkinsonism patients treated with levodopa (L-dopa) at the UCLA School of Medicine Neurology Clinic, neurologists observed that a sizeable number of patients reported an improvement in their thinking. In general, the patients described the change as being able to think faster and more clearly. This beneficial side-effect has also been mentioned briefly by Cotzias, Papavasiliou, and Gellene (1969), Godwin-Austen, Tomlinson, Frears, and Kok (1969), and Wycis, Cunningham, Kellett, and Spiegel (1970) who refer to the change as an 'awakening' or 'alerting' effect. Very little information has been published on the precise nature of the awakening effect. Although the beneficial action of levodopa in ameliorating akinesia, rigidity, and tremor has been well-documented (Cotzias et al., 1969; GodwinAusten et al., 1969; Klawans and Garvin, 1969; Mawdsley, 1970; Treciokas, Markham, and Ansel, submitted 1970; Wycis et al., 1970; Yahr, Duvoisin, Schear, Barrett, and Kessler, 1970), patients with the greatest motor improvement do not necessarily show improved thinking ability (Godwin-Austen et al., 1969). Cotzias et al. (1969) were unable to relate some of their patient's enhanced thinking ability to either physical improvement or to withdrawal of previous anti-Parkinsonism medications. Factors related to changes in thinking, apparently, are not always associated with improvement in motor control or proficiency. Since symptomatic relief does not appear to be the causal factor behind the improved thinking capacity, a psychological investigation was initiated in the summer of 1969 at the UCLA Neurology Clinic to delineate some of the factors underlying the apparent improved thinking observed in some patients by measuring the effects of levodopa on auditory and visual perception, short-term memory and verbal learning, and emotional functioning - all areas of mental functioning potentially capable of influencing the speed and efficiency of thinking.

Since impaired perception impedes efficient thinking, various aspects of perception were investigated, such as measuring visual and auditory thresholds by determining the minimum exposure rates at which Parkinsonism patients perceive visual and auditory stimuli. Alphabet letters were exposed tachistoscopically at increasing exposure rates calibrated in 
milliseconds until the patient recognized the letter. In determining auditory perceptual thresholds, the patient judged the second tone as being either longer or shorter in 50 pairs of two tones differing in time duration from 50 to $300 \mathrm{msec}$.

The possibility that improvement in intellectual functioning may be related to improved short-term memory or immediate recall was also explored by testing the patients' auditory and visual short-term memory spans of both familiar and unfamiliar stimuli. The short-term memory span is defined in the study as the amount of either auditory or visual stimuli that can be registered by the patient immediately after one stimulus presentation. Auditory short-term memory spans of familiar material were measured by having the patient recall series of numbers and sentences played to him by a tape recorder. To test for visual short-term memory span, the patient viewed 10 ink drawings of familiar objects for five seconds and then attempted to recall them. Because recall of familiar stimuli is a relatively easy task and one which might not be disrupted by Parkinson's disease, short-term memory spans of unfamiliar material, a more difficult task, were investigated. Auditory short-term memory spans of unfamiliar stimuli were obtained by having the patient discriminate between 30 similar and dissimilar pairs of rhythmic patterns and in identifying the discordant note in 30 pairs of brief melodies. After the stimuli were presented, the patients were allowed as much time as was needed to answer.

The presence of depression can also be a factor in slowing down and interfering with an individual's thinking and learning capacity. Yahr et al. (1969) stated that a feeling of well-being and renewed interest in family life replaced feelings of depression and apathy in most of their patients after levodopa therapy was initiated. Because the Parkinsonism patient has often been described in the literature as being depressed (Warburton, 1967a; Mindham, 1970), the possibility that levodopa's beneficial effects on slowed thinking may be related to the amelioration of an underlying depression needed to be evaluated. The Minnesota Multiphasic Personality Inventory (MMPI) (Dahlstrom and Welsh,1960), which gives objective scores on a number of relevant personality characteristics, emotional and physical functioning, was selected as the test instrument. The MMPI, a true-false questionnaire, consists of 566 statements to which the subject answers either true, false, or cannot say. The underlying assumption of this test is that individuals who are similar in important aspects of their personality and behaviour will tend to answer the questions in a similar pattern. The statements, which were selected empirically on the basis of being able to differentiate specific psychiatric patient groups from normal subjects, $\frac{O}{Z}$ have been assembled into 10 clinical scales. Scale 2 , the depression scale, is particularly pertinent to the study because it is a measure of mood fluctuation $\stackrel{\infty}{=}$ and subtle changes in morale. Elevations on this $\widehat{0}$ scale are associated with depression, pessimism, feel- $D$ ings of worthlessness and hopelessness, slowing of thought and action, and frequent thoughts of suicide $\frac{}{\mathrm{O}}$. and death (Dahlstrom et al., 1960; Good and Brantner, 1961).

Most Parkinsonism patients were tested before $\overrightarrow{\vec{\sigma}}$ receiving levodopa and retested approximatelyo three months after they had been on the medication. 흘 Since improvement in psychological test scores may $\frac{\overline{\bar{p}}}{2}$ reflect influences other than those inherent in the $\frac{\mathbb{Q}}{\Omega}$ experimental variable, such as familiarization with the testing situation, increased rapport with the ${ }^{\infty}$ experimenter, and practice effects on retest, a $\vec{\circ}$ control group was tested on the identical test battery. $\overrightarrow{\vec{\omega}}$ The control subjects, equated with the Parkinsonism ${ }_{\mathscr{S}}$ patients on age, educational level, and verbal IQ, were retested after a comparable time interval.

METHOD AND MATERIALS

SUBJECTS The experimental group consisted of 23 mes and six women in levodopa therapy between July 1969 工 and June 1970. An additional four patients were nबit $\vec{c}$ retested because levodopa was either temporarily or permanently discontinued; and one other patient refusogd further psychological testing. The 29 patients ranged $\rightarrow$ age from 44 to 71 years, with a mean age of 58.69 yeds, SD of 6.77. Patients' duration of illness ranged from ninte.months to 34 years, $\bar{X}$ of 7.41 years, \pm 6.67 . Three patients had right cryothalamectomies; three patients had left cryothalamectomies, and two patients had bilateral thalamotomies. The patients had been operated on 10 months to 10 years before being tested. All patients $\frac{\not}{\mathbb{Q}}$ obtained verbal intelligence scores in the average to $\propto$ superior range with a mean IQ of $110 \cdot 24$, and a SD of $\overrightarrow{\overrightarrow{0}}$ 11.95 . Educationally as well as intellectually they scored 3 above average; mean years of formal schooling were $14 \cdot 34$, SD of 3.90. Twenty-six patients were tested fromo 71 to 119 days after beginning levodopa. Two patients were retested after 248 and 253 days, respectively. Twenty-four patients were on supplementary anti-o cholinergic anti-Parkinsonism medication initially. Five $\frac{\sigma}{3}$ patients began levodopa therapy free of supplementary. anticholinergic medications. At time of retest, 10 patientso were taking levodopa exclusively and 19 were taking supplementary anti-Parkinsonism medications.

Patients were evaluated for disability stages ranging $\frac{\text { ? }}{2}$ from (0) no discernible involvement; (1) unilateral involvement only; (2) bilateral involvement only; (3) first evidence of impaired postural and righting reflexes $N$ by examination or by history of poor balance, falling, etc. Disability mild to moderate; (4) fully developed severe $N$ disease, disability marked; (5) confinement to bed or wheelchair. Most patients were rated as being mildly or 
moderately disabled. See Table 1 for further information on descriptive characteristics.

CONTROLS Thirty-two control subjects were tested. The controls were either female or male employees or volunteer workers at the UCLA Hospital, physiotherapy patients without CNS disease, or relatives of the Parkinsonism patients. Descriptive characteristics of the control subjects are presented in Table 1. The two groups did not differ significantly from each other in age, verbal IQ or educational level. The two groups are thus comparable on relevant characteristics that might influence their test scores.

PROCEDURE The psychological tests were included in a larger evaluation study of patients undergoing levodopa treatment. All patients were requested to take the tests before beginning levodopa. All but two patients were tested before levodopa therapy. One patient was tested after taking levodopa for six days; the other one after four days. Since the first therapeutic effects of levodopa appear no earlier than two to three weeks, the initial tests on these two patients were included with the other initial scores.

All experimental psychological tests were administered in two forms to control for practice effects related to retaking an identical test. To control for the possibility of one form being easier than the other, half the patients and the controls received Form $\mathrm{A}$ first and later were retested on Form B. The test sequence was reversed for the remaining subjects. To provide uniformity, all test instructions and auditory stimuli were tape recorded. Tape recorder volume was adjusted individually for each subject. The three standardized tests used in the test battery were the Seashore Tests for Musical Talents (Seashore, Lewis, and Saetveit, 1960), the Minnesota Multiphasic Inventory (MMPI), and the verbal part of the Wechsler Adult Intelligence Scale (WAIS) (Wechsler, 1955). Among the many advantages in using the Seashore subtests are that they are relatively unfamiliar to most subjects, are carefully prepared, and recorded on tape, thus ensuring that each subject is exposed to the same stimuli. Although there is no alternative form for the Seashore subtests, practice effects are minimal and can be ascertained by any improvement occurring in the control group's scores. Practice effects on the MMPI, which is a true-false personality test, are irrelevant, since changes in test-retest answers reflect valid changes in the patients' personality, character traits, physical, and emotional functioning even over a relatively short time. The WAIS was administered only during the initial testing to obtain an intelligence test score for each subject and was not repeated on retest. Since the Parkinsonism patients would have been unduly penalized on the Performance subtests because of their motor impairments, it was decided to administer only the verbal subtests. The WAIS scores were used only to equate the Parkinsonism group with the control group. In addition, various motor tasks were performed by the patients and control subjects. Results on changes in motor performance and a more detailed report on the personality test are to be reported in subsequent papers.

\section{EXPERIMENTAL TESTS}

AUDITORY PERCEPTUAL TEST The Time subtest of the Seashore Measures of Musical Talents was selected to investigate auditory perception. The Time test (referred to in the study as the Tone Duration test) consists of 50 pairs of tones differing in duration from 0.05 to 0.30 seconds. The tone frequency is held constant at 440 cycles. The subject has to decide if the second tone is longer or shorter than the first tone. Instructions were modified to fit the experimental task and tape recorded.

TABLE 1

DESCRIPTIVE CHARACTERISTICS

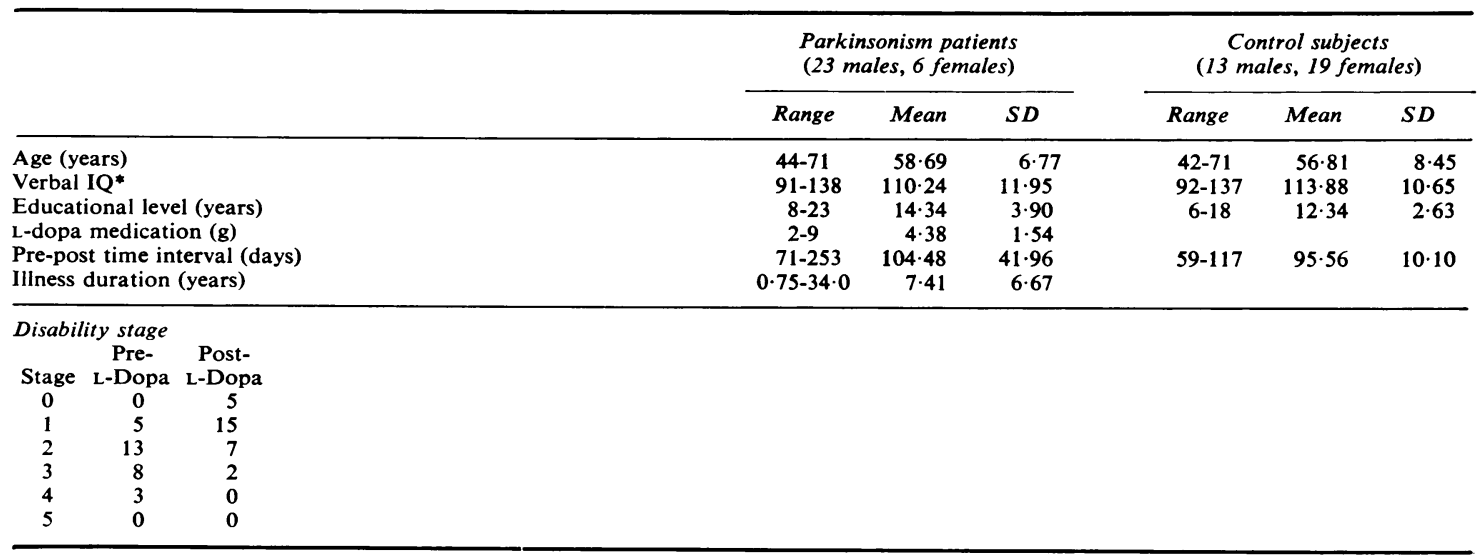

*Satz and Mogel abbreviated WAIS (1962). 
VISUAL PERCEPTUAL TEST Two series of alphabet letters matched for general physical configurations, d-p-w-h (Form A) and b-g-m-k (Form B), were selected. These letters were printed individually on white cardboard and exposed tachistoscopically beginning at $5 \mathrm{msec}$ and exposed twice at each exposure reading. The letter presented twice at each exposure reading was exposed at increasing time exposures until it was recognized by the subject.

AUDITORY SHORT-TERM MEMORY TESTS The Tonal Memory and Rhythm sub-tests of the Seashore Measures of Musical Talents were selected to investigate the shortterm memory of unfamiliar auditory material. Both subtests present relatively unfamiliar, novel auditory stimuli which the subjects must recall accurately immediately afterwards. The Tonal Memory test (referred to in the study as the Melody test) contains 30 pairs of short melodies in which one note has been changed in the second pair. The subject must decide which note is different. The melodies consist of three, four and five note melodies. The Rhythm test has 30 pairs of rhythmic patterns. Some of the pairs are the same and some are different. The frequency of the rhythm stimuli is 500 cycles; the tempo is constant at the rate of 92 quarter notes per minute. The initial 10 rhythms are five note patterns, the next 10 are six note patterns, and the last 10 rhythm pairs are seven note patterns.

Short-term memory of familiar material consisted of recalling digits forward and backward and recalling a series of tape recorded sentences. Two parallel forms were constructed for these tests. The sentences based on the Spreen-Benton Sentence Repetition test (Spreen and Benton, 1963) increased in length and complexity from easy to difficult sentences. This test was discontinued after five consecutive failures and discontinued on the digits test after two consecutive failures on the same series of numbers.

VISUAL SHORT-TERM MEMORY Two experimental $9 \times 12$ inch cards with 10 familiar objects drawn on each were shown to each subject for five seconds. The subject was immediately asked to recall as many of the 10 objects as he could.

VERBAL LEARNING A paired associates learning test was constructed to investigate new verbal learning ability. The paired associates learning test has been widely reported in the literature as one of the main tests used to study the effects of brain damage on memory (Milner and Teuber, 1968). The words selected for the study were all nouns, equated for difficulty level and for word frequency (Thorndike and Lorge, 1944). Each form had six pairs, three pairs were somewhat related to each other conceptually, such as yard-garden, land-ocean, inchnumber, whereas the other three pairs had no common association and were more difficult to learn, such as queen-butter, heat-people, and month-uncle. The word pairs and instructions were presented by a tape recorder. Each subject was given five trials to learn the word pairs.

ALERTNESS OR CONCENTRATION TESTS Several tests were arbitrarily categorized as measures of alertness or con- $Z$ centration, since the subject had to rely on knowledge he $\stackrel{\mathbb{D}}{C}$ already possessed and did well if he was alert. The Free Association test required the subject to say all the words he could think of in 60 seconds beginning with $t$ (Form $A)$ or d (Form B). These two letters were selected because 7 research findings suggest they tend to elicit about the? same number of associations (Anderson, 1965). The $\frac{\rho}{\square}$ subjects were also asked to read a descriptive paragraph which was typed in extra large print on a $5 \times 8$ inch card. The two paragraphs were equated for difficulty level $\Rightarrow$ (8th to 11th grade level) (Davis and Davis, 1962), and each contained 229 letters.

PERSONALITY TEST The Minnesota Multiphasic Person- $-\frac{\overline{\bar{c}}}{\bar{D}}$ ality Inventory was answered twice by each subject at $\vec{\sigma}$ the beginning of the testing and again at the conclusion $\propto$ of the retesting. The test consisted of 566 statements ${ }_{0}$ relating to all aspects of physical and emotional function- $\vec{O}$ ing and problems and provides an objective measure of ${ }^{\circ}$ the individual's emotional functioning.

\section{MEDICATION PROCEDƯRE}

If the patients were taking anticholinergic medications $\omega$ and/or amantadine hydrochloride, they were continued $\stackrel{+}{\omega}$ at the same modest dosage until the optimum dosage of in levodopa was reached. For example, trihexyphenidigl 0 $\mathrm{HCl}$ (Artane) was continued at $2 \mathrm{mg}$ two or three tims a day, and benztropine mesylate (Cogentin) at a dosage of 1 to $2 \mathrm{mg}$ a day. These drugs were then stopped observe the therapeutic effect of levodopa alone; in mogt $\subseteq$ instances this procedure was done at a time other than $\bar{D}$ when the psychological retests were performed. Of the 29 patients, 19 were on the same anticholinergic mediof tions at the time of the initial test and retest examinations, five patients who had been taking anticholinergic medications had these discontinued and were on levodopa ex-乏 clusively when retested; and five patients were not taking supplementary anticholinergic medications before or@ during the levodopa trial. Digitalis, diuretics, and other $\frac{\circ}{\circ}$ medications without central nervous system effects were $\varrho$ continued unchanged.

The levodopa was started at a daily dosage of $0.5 \mathrm{~g}$ and 3 was increased by $0.5 \mathrm{~g}$ every three or four days until a level of $3.0 \mathrm{~g}$ was reached. Further increase was done more gradually. All the patients in the present series had reached their optimum dosages by the second month, about one month before the psychological retests were? administered.

\section{RESULTS}

PERCEPTION In perceiving auditory stimuli (Table윽 2), patients with Parkinsonism significantly im- $\rightarrow$ proved their perceptual score on the Tone Duration test $(\mathrm{t}=2.86, \mathrm{P}<0.01)$. Although the controlĩ group perceived time differences more accurately ${ }^{\circ}$ on both pre- and post-tests than did the Parkin- $N$ sonism patients, they did not improve their auditory N perceptual score $(\mathrm{t}=0.49,0.60<\mathrm{P}<0.70)$. Ofo 
the 13 patients showing the greatest improvement in auditory perception, four had been taking levodopa exclusively; four had been on supplementary antiParkinsonism medication at the beginning of the study but were discontinued on it during the study, and five were continued on the same supplementary medications. In those patients whose supplementary anti-Parkinsonism medications were discontinued, the dosage levels had not been high and were probably of no significance in influencing cognitive functioning at the pre-levodopa testing. Thus, there is no evidence to support the hypothesis that it is the discontinuation of supplementary anti-Parkinsonism medication that accounts for the patients' improved perceptual ability.

There were no comparable test data found for improved visual perception. Although the results of the visual perceptual test indicate lower visual thresholds at retest for both the patient and control groups, these improved scores were not statistically significant. For the Parkinsonism patient group, $t=1 \cdot 31, P=0.20$; for the control group, $t=1 \cdot 43$, $0 \cdot 10<\mathrm{P}<0 \cdot 20$.
SHORT-TERM MEMORY In repeating sentences and digits forward and backward, neither the Parkinsonism group nor the control group gave any test evidence of improving their short-term memory scores of familiar auditory stimuli (Table 3 ). For the Parkinsonism group, $t$-scores for Sentence Repetition was $t=1.60,0.10<P<0.20$; digits forward, $t=1.73, P=0.10 ;$ and for digits backward, $t=$ $1 \cdot 75, P=0 \cdot 10$. Control group's $t$ score for Sentence Repetition was $0.24,0.80<\mathbf{P}<0.90$; digits forward, $\mathrm{t}=0.47,0.60<\mathrm{P}<0.70$; for digits backward, $\mathrm{t}=1.35,0.10<\mathrm{P}<0.20$.

In the recall of unfamiliar auditory stimuli (Table $3)$, both the patient $(t=2.86, P<0.01)$ and control groups $(\mathrm{t}=2.26, \mathrm{P}<0.05)$ improved significantly on the Melody test (Table 3). Neither group showed a statistically significant improvement on the Rhythm test: Parkinsonism group, $\mathrm{t}=1 \cdot 17,0.20<$ $\mathrm{P}<0.30$; control group, $\mathrm{t}=0.50,0.60<\mathrm{P}<0.70$.

Both Parkinsonism patients and control subjects demonstrated improved recall of visual objects on retest, $\mathrm{t}=2.10, \quad \mathrm{P}<0.05 ; \mathrm{t}=2.40, \quad \mathrm{P}<0.05$, respectively.

TABLE 2

AUDITORY AND VISUAL PERCEPTION

\begin{tabular}{|c|c|c|c|c|c|c|c|c|c|c|}
\hline \multirow[t]{3}{*}{ Test } & \multicolumn{5}{|c|}{ Parkinsonism patients } & \multicolumn{5}{|c|}{ Control subjects } \\
\hline & \multicolumn{2}{|c|}{ Mean } & \multirow[t]{2}{*}{ t-Score } & \multicolumn{2}{|c|}{$S D$} & \multicolumn{2}{|c|}{ Mean } & \multirow{2}{*}{ t-Score } & \multicolumn{2}{|c|}{$S D$} \\
\hline & Pre-test & Post-test & & Pre-test & Post-test & Pre-test & Post-test & & Pre-test & Post-test \\
\hline \multirow{4}{*}{$\begin{array}{l}\text { Auditory perception } \\
\text { Tone duration (msec) } \\
\text { Visual perception } \\
\text { Letters (msec) }\end{array}$} & & & & & & & & & & \\
\hline & $31 \cdot 35$ & $35 \cdot 86$ & $2 \cdot 86^{*}$ & $10 \cdot 72$ & $9 \cdot 80$ & $39 \cdot 53$ & $39 \cdot 81$ & $0.49 \mathrm{NS}$ & $4 \cdot 38$ & 3.93 \\
\hline & & & 12NC & & & $20=7$ & 2509 & & & 10,6 \\
\hline & 45.89 & $39 \cdot 80$ & $1.31 \mathrm{NS}$ & 24.94 & $26 \cdot 67$ & $39 \cdot 57$ & 35.63 & $1.43 \mathrm{NS}$ & $22 \cdot 64$ & $18 \cdot 66$ \\
\hline
\end{tabular}

$* P<0.01$.

NS $=$ Non-significant.

TABLE 3

AUDITORY AND VISUAL SHORT-TERM MEMORY AND LEARNING

\begin{tabular}{|c|c|c|c|c|c|c|c|c|c|c|}
\hline \multirow[t]{3}{*}{ Test } & \multicolumn{5}{|c|}{ Parkinsonism patients } & \multicolumn{5}{|c|}{ Control subjects } \\
\hline & \multicolumn{2}{|c|}{ Mean } & \multirow[t]{2}{*}{$t$-Score } & \multicolumn{2}{|c|}{$S D$} & \multicolumn{2}{|c|}{ Mean } & \multirow[t]{2}{*}{ t-Score } & \multicolumn{2}{|c|}{$S D$} \\
\hline & Pre-test & Post-test & & Pre-test & Post-test & Pre-test & Post-test & & Pre-test & Post-test \\
\hline \multicolumn{11}{|l|}{ Auditory stimuli tests } \\
\hline Digits-forward & $6 \cdot 52$ & 6.90 & $1 \cdot 73 \mathrm{NS}$ & $1 \cdot 21$ & $1 \cdot 11$ & $7 \cdot 19$ & $7 \cdot 09$ & $0.47 \mathrm{NS}$ & 1.00 & $1 \cdot 00$ \\
\hline Digits-backward & $4 \cdot 59$ & $4 \cdot 24$ & $1 \cdot 75 \mathrm{NS}$ & $1 \cdot 32$ & $1 \cdot 38$ & 5.09 & $5 \cdot 41$ & $1 \cdot 35 \mathrm{NS}$ & $1 \cdot 12$ & $1 \cdot 29$ \\
\hline Digits-total & $11 \cdot 10$ & $11 \cdot 14$ & $0 \cdot 18 \mathrm{NS}$ & $2 \cdot 07$ & $2 \cdot 27$ & $12 \cdot 28$ & $12 \cdot 50$ & $0.77 \mathrm{NS}$ & $1 \cdot 73$ & 1.97 \\
\hline Sentence repetition & $17 \cdot 10$ & $17 \cdot 79$ & $1 \cdot 60 \mathrm{NS}$ & $3 \cdot 59$ & $3 \cdot 56$ & $18 \cdot 84$ & $18 \cdot 91$ & $0 \cdot 24 \mathrm{NS}$ & 3.03 & $2 \cdot 96$ \\
\hline Melody & $19 \cdot 45$ & $21 \cdot 45$ & $2 \cdot 86 \dagger$ & $7 \cdot 65$ & $6 \cdot 77$ & $21 \cdot 37$ & $22 \cdot 41$ & $2 \cdot 26^{*}$ & $6 \cdot 54$ & 6.07 \\
\hline Rhythm & $22 \cdot 21$ & $23 \cdot 38$ & $1 \cdot 17 \mathrm{NS}$ & $6 \cdot 25$ & $4 \cdot 46$ & $25 \cdot 28$ & $25 \cdot 50$ & $0.50 \mathrm{NS}$ & $2 \cdot 45$ & $2 \cdot 92$ \\
\hline \multicolumn{11}{|l|}{ Visual stimuli test } \\
\hline Recall of visual objects & $3 \cdot 79$ & $4 \cdot 21$ & $2 \cdot 10^{*}$ & $1 \cdot 65$ & $1 \cdot 57$ & $4 \cdot 75$ & $5 \cdot 37$ & $2 \cdot 40^{*}$ & $1 \cdot 27$ & $1 \cdot 58$ \\
\hline Verbal learning task & & & & & & & & & & \\
\hline Paired associates & $14 \cdot 69$ & $17 \cdot 48$ & $2 \cdot 43 *$ & $7 \cdot 14$ & $6 \cdot 90$ & $22 \cdot 09$ & $22 \cdot 28$ & $0 \cdot 20 \mathrm{NS}$ & $5 \cdot 18$ & $4 \cdot 24$ \\
\hline
\end{tabular}

$* P<0.05$

$+\mathrm{P}<0.01$.

NS $=$ Non-significant. 
Since the control group improved on the same tests as the Parkinsonism group, the visual recall test and the Melody test, the improvement shown by the Parkinsonism group appears to be related to practice effects rather than to changes related to levodopa medication. Thus, the test findings in the study do not support the contention that levodopa improves immediate recall ability of both familiar and unfamiliar auditory and visual stimuli.

VERBAL LEARNING In learning word pairs on the Paired Associates test, the Parkinsonism group increased their scores from a mean of 14.69 on pretest to 17.48 on post-test out of a possible score of 30 (Figure), demonstrating an improved learning capacity after levodopa therapy $(\mathrm{t}=2.43, \mathrm{P}<0.05$, Table 3). Of those patients who improved their score by at least five points, seven continued their supplementary anti-Parkinsonism medication at the pre-levodopa level, two patients' supplementary medications were discontinued, and two patients had been taking levodopa exclusively. In the two patients whose supplementary anti-Parkinsonism medications were discontinued, their medication levels had been low and probably of no significance in interfering with cognitive functioning at time of initial testing. The improved verbal learning ability appears to be related to the levodopa medication and not to changes in supplementary anti-Parkinsonisn' $\bar{Z}$ medication. The control group did not improve their $\stackrel{\mathbb{\perp}}{\subset}$ scores $(t=0.21,0.80<P<0.90$, Table 3$)$.

ALERTNESS OR CONCENTRATION INDICES The Parkinsonism group did not improve their scores on tests primarily requiring alertness or concentration, Free Association $(t=0.38,0.70<P<0.80)$, or in reading a paragraph $(\mathrm{t}=1.88,0.05<\mathbf{P}<0.10)$ 疋 The observed improvement in auditory perception and verbal learning tasks cannot be attributed to an increase in alertness or concentration on retesto (Table 4). The control group's scores showed no을 improvement from pre-test to post-test on these two $\frac{\bar{s}}{\frac{1}{6}}$ tests.

DEPRESSION SCORES Although the Parkinsonism group's depression score on the MMPI was less on? retest, $\overline{\mathrm{X}}$ of 79.37 versus 81.33 , the change is non- $\overrightarrow{\vec{\omega}}$ significant statistically and is a difference that could $\stackrel{\omega}{\omega}$ have occurred by chance, $t=0.91,0.30<P<0.40$. Both on pre- and post-test, the Parkinsonism patients 0 can be described as scoring in the moderate to severe ${ }_{\perp}^{\omega}$ range of depression. Since their score did not change $\omega$ significantly on retest, there are no objective tefist data to suggest that improvement in auditory perced 6 tion or learning ability is related to a lessening of an underlying depression.

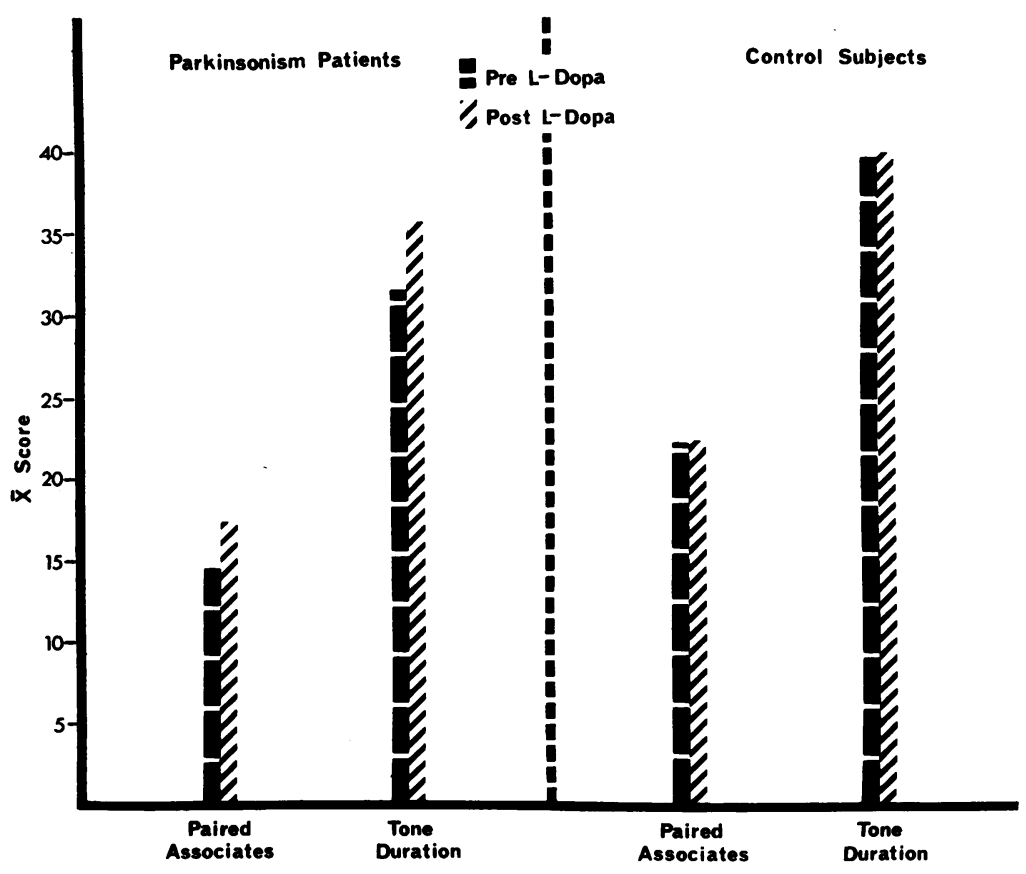

FIGURE Parkinsonism and control group mean scores on the Paired Associates and Tone Duration tests. 
TABLE 4

ALERTNESS TESTS

\begin{tabular}{|c|c|c|c|c|c|c|c|c|c|c|}
\hline \multirow[t]{3}{*}{ Test } & \multicolumn{5}{|c|}{ Parkinsonism patients } & \multicolumn{5}{|c|}{ Control subjects } \\
\hline & \multicolumn{2}{|c|}{ Mean } & \multirow[t]{2}{*}{$t$-Score } & \multicolumn{2}{|c|}{$S D$} & \multicolumn{2}{|c|}{ Mean } & \multirow[t]{2}{*}{$t$-Score } & \multicolumn{2}{|c|}{$S D$} \\
\hline & Pre-test & Post-test & & Pre-test & Post-test & Pre-test & Post-test & & Pre-test & Post-test \\
\hline Free association & $15 \cdot 38$ & $15 \cdot 03$ & $0.38 \mathrm{NS}$ & $7 \cdot 18$ & $7 \cdot 39$ & $17 \cdot 34$ & $17 \cdot 97$ & $0.86 \mathrm{NS}$ & 6.02 & $6 \cdot 08$ \\
\hline Reading paragraph & $18 \cdot 71$ & $17 \cdot 64$ & $1 \cdot 88 \mathrm{NS}$ & 5.05 & 4.96 & 16.03 & 15.98 & $0.09 \mathrm{NS}$ & $3 \cdot 47$ & $2 \cdot 98$ \\
\hline
\end{tabular}

NS $=$ Non-significant.

EVIDENCE OF MILD IMPAIRMENT IN PATIENTS WITH PARKINSONISM The Parkinsonism group consistently scored below that of the control group on all the experimental tests in spite of being equated for age, verbal IQ, and educational level. Although not all these differences were statistically significant, the majority of them were (Table 5). In particular on the pre-levodopa tests, the Parkinsonism group scored significantly below the control group's scores on auditory perception, verbal learning, digits forward, sentence repetition, rhythm, recall of visual objects, and paragraph reading time. The two groups did not differ on pre-test on digits backward, the Melody test, number of free associations or in visual thresholds.

Post-test scores reveal fewer significant differences between the Parkinsonism and control groups. The control group maintained their superior scores on auditory perception, verbal learning, rhythm, and recall of visual objects. On retest, the Parkinsonism group recalled fewer digits backward than the control group, whereas on pre-test the Parkinsonism patients recalled fewer digits forward. On retest, the control group no longer scored above the Parkinsonism group on sentence repetition or paragraph reading time. Both on pre-test and post-test, there were no significant differences between the two groups on the Melody test, Free Association test, or visual thresholds.

Thus, in spite of motor impairment being the outstanding symptom in Parkinson's disease, evidence for mild impairment of the higher mental functions is indicated even in a group of Parkinsonism patients whose intellectual functioning is relatively intact.

\section{DISCUSSION}

A generalized 'awakening' or 'alerting' reaction in which an increase in alertness and concentration occurs was not supported by the test findings. The Parkinsonism group performed as well on various tests of alertness and concentration before levodopa

TABLE 5

EVIDENCE OF MILD IMPAIRMENT IN PARKINSONISM PATIENTS

\begin{tabular}{|c|c|c|c|c|c|c|}
\hline \multirow{2}{*}{$\begin{array}{c}\text { Test } \\
\text { Perceptual } \\
\text { Tone duration (auditory) }\end{array}$} & \multicolumn{2}{|c|}{ Pre-test mean } & \multirow{2}{*}{$\begin{array}{l}t-S c o r e \\
3 \cdot 87_{t}^{t}\end{array}$} & \multicolumn{2}{|c|}{ Post-test mean } & \multirow{2}{*}{$\begin{array}{l}t-S c o r e \\
2 \cdot 10^{*}\end{array}$} \\
\hline & $\begin{array}{l}\text { Parkinson } \\
31 \cdot 55\end{array}$ & $\begin{array}{l}\text { Control } \\
39.53\end{array}$ & & $\begin{array}{l}\text { Parkinson } \\
35 \cdot 86\end{array}$ & $\begin{array}{l}\text { Control } \\
39 \cdot 81\end{array}$ & \\
\hline Letters (visual) & $45 \cdot 89$ & $39 \cdot 57$ & $1 \cdot 02 \mathrm{NS}$ & $39 \cdot 80$ & $35 \cdot 63$ & $0.65 \mathrm{NS}$ \\
\hline \multicolumn{7}{|l|}{$\begin{array}{l}\text { Short term memory } \\
\text { Auditory }\end{array}$} \\
\hline $\begin{array}{l}\text { Digits forward } \\
\text { Digits backward } \\
\text { Sentence repetition } \\
\text { Paired associates } \\
\text { Melody } \\
\text { Rhythm } \\
\text { Visual }\end{array}$ & $\begin{array}{r}6 \cdot 52 \\
4 \cdot 59 \\
17 \cdot 10 \\
14 \cdot 69 \\
19 \cdot 45 \\
22 \cdot 21\end{array}$ & $\begin{array}{r}7 \cdot 19 \\
5 \cdot 09 \\
18 \cdot 84 \\
22 \cdot 09 \\
21 \cdot 37 \\
25 \cdot 28\end{array}$ & $\begin{array}{l}2 \cdot 37^{*} \\
1 \cdot 60 \mathrm{NS} \\
2 \cdot 05^{*} \\
4 \cdot 67^{\ddagger} \\
1 \cdot 06 \mathrm{NS} \\
2 \cdot 57^{*}\end{array}$ & $\begin{array}{r}6 \cdot 90 \\
4 \cdot 24 \\
17 \cdot 79 \\
17 \cdot 48 \\
21 \cdot 45 \\
23 \cdot 38\end{array}$ & $\begin{array}{r}7 \cdot 09 \\
5.41 \\
18.91 \\
22 \cdot 28 \\
22 \cdot 41 \\
25 \cdot 50\end{array}$ & $\begin{array}{l}0 \cdot 73 \mathrm{NS} \\
3 \cdot 42 \dagger \\
1 \cdot 34 \mathrm{NS} \\
3 \cdot 31 \dagger \\
0 \cdot 58 \mathrm{NS} \\
2 \cdot 22^{*}\end{array}$ \\
\hline $\begin{array}{l}\text { Recall of objects } \\
\text { Tests of alertness }\end{array}$ & $3 \cdot 79$ & $4 \cdot 75$ & $2 \cdot 55^{*}$ & $4 \cdot 21$ & $5 \cdot 37$ & $2 \cdot 90 \dagger$ \\
\hline $\begin{array}{l}\text { Free association } \\
\text { Reading paragraph }(\mathrm{Sec})\end{array}$ & $\begin{array}{l}15 \cdot 38 \\
18 \cdot 71\end{array}$ & $\begin{array}{l}17 \cdot 34 \\
16 \cdot 03\end{array}$ & $\begin{array}{l}1 \cdot 16 \mathrm{NS} \\
2 \cdot 44^{*}\end{array}$ & $\begin{array}{l}15 \cdot 03 \\
17 \cdot 64\end{array}$ & $\begin{array}{l}17 \cdot 97 \\
15 \cdot 98\end{array}$ & $\begin{array}{l}1 \cdot 70 \mathrm{NS} \\
1 \cdot 60 \mathrm{NS}\end{array}$ \\
\hline
\end{tabular}


as afterwards. Previous research (Godwin-Austen et al., 1969; Wycis et al., 1970) mentioning the awakening effect specifically refer to the patient's becoming more alert, but no objective test scores were offered to corroborate the statement nor were there any clinical or objective descriptions given on the patients who demonstrated the awakening effect. It is possible that the patients who showed the awakening effect in the previous research studies were not as intellectually alert or well-orientated as the patients described in this study. A more impaired group of Parkinsonism patients than those patients in the present study may respond to levodopa with a generalized awakening effect.

Cotzias et al. (1969) suggest the awakening effect to be one of improved memory, a healthier outlook, and a diminution of apathy and listlessness. On the majority of auditory and visual short-term memory tests, the Parkinsonism group did not improve their immediate memory scores; on the few short-term memory tests where improvement did occur, similar results occurred in the control group, suggesting that a practice effect was responsible for the improvement. It may be argued that the tests measuring auditory and visual short-term memory, attention, and concentration may have been too easy for the Parkinsonism group and that the tests were not capable of detecting subtle changes. The Parkinsonism group was, in general, an intellectually bright, well-educated group with some of its members still actively employed in responsible occupations and with only a few patients demonstrating intellectual impairment characteristic of mild organic brain damage. The fact that the Parkinsonism group, in spite of being matched with the control group on verbal IQ, educational level, and age, scored significantly below the control group on the majority of these short-term memory and attention tests (to be discussed later in this paper) suggests that the tests were not too easy. Thus, there is no test evidence that improved cognitive functioning after levodopa therapy consists of improvement in auditory or visual short-term memory or in the ability to concentrate. If there had been a generalized awakening effect from levodopa, the Parkinsonism group should have improved their post-test scores significantly over the scores of the control group on tests of attention, concentration, and short-term memory.

If the improvement in cognitive functioning after levodopa treatment is more in the nature of ameliorating an organic memory deficit than an alerting or attentional defect, disorders of retention rather than immediate memory span are to be expected (Williams, 1968). Talland (1962) concluded from his investigation of Parkinsonism patients' cognitive functioning that their retention of new material after one hour is impaired and that this impairment $\underset{\mathbb{Q}}{Z}$ is related to Parkinson's disease and is probably aggravated by anti-Parkinsonism medication. In of this study, the Parkinsonism patients' improvements appear to be related to an enhanced learning capacity 0 and improved auditory perception. The improve- $\stackrel{\infty}{\stackrel{\infty}{S}}$ ment on the Paired Associates test, a verbal learning test of retention, supports Talland's contention that $\stackrel{0}{\rightleftarrows}$ Parkinson's disease specifically impairs the ability?. to retain new material-an intermediate to longterm memory function. This improvement in memorizing new verbal material also supports the hypothesis of Cotzias et al. that the awakening $\frac{\bar{\sigma}}{\bar{D}}$ effect includes a memory component which is $\frac{\vec{\sigma}}{\sigma}$ selective. Levodopa improves intermediate memory $\cong$ but not short-term memory. Improvement in verbal retention appears to reflect enhanced intellectual $\vec{\circ}$ functioning that is independent of increased alert- $\overrightarrow{\vec{H}}$ ness, lessening of depression, changes in supple- $\vec{\omega}$ mentary anti-Parkinsonism medication or improved motor ability or control.

Although there was no test evidence suggesting that a decrease in supplementary anti-Parkinsonism $\stackrel{+}{\omega}$ medication was responsible for the Parkinsonis group's improvement, the study was not designed to investigate the specific effects of supplementar 응 anti-Parkinsonism medication. Supplementary medf독cation was not discontinued but was continued if the $c$ patient benefited from its continuation. Therefore comments regarding the role of supplementar medication are tentative and incomplete and shoud be viewed as suggestive only.

The results of the present study suggest that improvement in intermediate memory functioning is related to levodopa therapy and that intermediate memory functioning, in fact, does improve with levodopa therapy. Further study of the effects of $\stackrel{\AA}{\propto}$ levodopa on retention of both auditory and visual $\overrightarrow{\vec{A}}$ materials appears promising and should be directed $\frac{O}{3}$ toward investigating memory retention over various $\bar{\gamma}$ time intervals from a few minutes to at least one hour after presenting the stimuli.

Objective test evidence of improved perceptual thresholds after levodopa therapy is equivocal. Although the control group did not improve their 3 auditory or visual thresholds, the Parkinsonism group significantly improved their auditory percep- $\frac{}{3}$ tual thresholds but showed no significant change in their visual threshold $(P=0 \cdot 20)$. This discrepancy $\frac{}{3}$ in changes in threshold levels between the two $\frac{D}{0}$ modalities may be related to the research design which tended to maximize intra- and inter-individual $\mathrm{N}$ differences in the visual threshold test. The task of $N$ recognizing single letters exposed individually in a tachistoscope appears to have been too unstable a $\mathrm{W}$ measure of visual thresholds. Visual thresholds 
ranged from $5 \mathrm{msec}$ to $120 \mathrm{msec}$ with a $\bar{X}$ of 45.89 msec and a SD of 24.94 for the Parkinsonism patients and from $5 \mathrm{msec}$ to $140 \mathrm{msec}$ with a $\bar{X}$ of 39.57 and a SD of 22.64 for the control subjects on initial testing. Stimulus recognition thresholds fluctuated widely suggesting that the subject's performance may have been overly influenced by momentary internal changes which were unrelated to the levodopa medication. Since the present test results are based on an unstable measure of visual thresholds, the visual recognition threshold test should be repeated using visual stimuli that require a longer recognition time, such as a phrase of words or short sentences.

The contention of Yahr et al. (1969) that Parkinsonism patients are less depressed and apathetic after being on levodopa was not supported by the study's findings. It is possible that not enough time had elapsed between the initiation of levodopa treatment and retest for changes in depressive symptomatology to occur. Retest at a later date after the patient's emotional adjustment to the improvement in symptoms has stabilized may reveal a lessening of depressive symptomatology.

Observations that intellectual deterioration frequently accompanies Parkinson's disease, particularly in the later stages of the disease, have been reported in the literature as early as 1881 (Warburton, 1967b; Asso, 1969b). Many of these studies have been based on clinical observations which lack verifiable objective measurements and control groups, thus rendering the extent and nature of the intellectual impairment ambiguous. In a study comparing Wechsler Adult Intelligence Scale test scores of Parkinsonism patients with the WAIS standardization group (Asso, 1969), the Parkinsonism group scored below the standardization group on subtests requiring use of the hands. The Parkinsonism group scored higher on subtests relying on verbal ability and reasoning. Talland (1962) reports some signs of cognitive and perceptual impairment in a group of Parkinsonism patients, but felt that there was no characteristic cognitive deficit associated with Parkinson's disease. His study was considerably restricted in the number of tests administered and may not have adequately sampled the patients' cognitive functioning, a shortcoming pointed out by Talland in his study. In addition, although Talland compared his Parkinsonism group with a control group, the groups were matched only by age and to some extent by sociocultural background. No control on educational background or verbal intelligence was included in his study, even though scores on cognitive tests in particular are highly correlated with intelligence.

The present study matched the Parkinsonism and control groups on more variables that might have had an influence on test scores. The results of these test scores strongly suggest the presence of mild cognitive impairment in a Parkinsonism group who scored on an intelligence test at the 75th percentile of the general population. Thus, in spite of being intellectually bright, well oriented, and above average in educational experiences, the Parkinsonism group, in general, scored below the control group on the majority of the tests.

It is unclear whether or not supplementary antiParkinsonism medication, depression, Parkinson's disease, or a combination of the three is responsible for this mild cognitive impairment. A study in which patients with Parkinsonism free of all anti-Parkinsonism medications are compared with a control group would be necessary to delineate the effects of Parkinson's disease exclusively.

The necessity of including a control group in evaluating the effects of medication over time is evident from the study. Many of the changes observed in the Parkinsonism group at time of retest also occurred in the control group and were apparently related to practice effects and familiarization with the testing situation even though alternative forms of most tests were used. Without a control group, spurious findings would have been reported.

We wish to thank Edward Kravitz, graduate student in clinical psychology, who so diligently administered the psychological tests to the majority of patients and control subjects and was helpful in all phases of the study.

\section{REFERENCES}

Anderson, N. S. (1965). Word associations to individual letters. J. verb. Learn. verb. Behav., 4, 541-545.

Asso, D. (1969). W.A.I.S. scores in a group of Parkinson patients. Brit. J. Psychiat., 115, 555-556.

Cotzias, G. C., Papavasiliou, P. S., and Gellene, R. (1969). Modification of Parkinsonism-chronic treatment with L-dopa. New Engl. J. Med., 280, 337-345.

Dahlstrom, W. G., and Welsh, G. S. (1960). An MMPI Handbook: A Guide to Use in Clinical Practice and Research. University of Minnesota Press: Minneapolis.

Davis, F. B., and Davis, C. C. (1962). Davis Reading Test Manual, Series 1 and 2. Psychological Corp: New York.

Godwin-Austen, R. B., Tomlinson, E. B., Frears, C. C., and Kok, H. W. L. (1969). Effects of L-dopa in Parkinson's disease. Lancet, 2, 165-168.

Good, P. K-E., and Brantner, J. P. (1961). The Physicians Guide to the MMPI. University of Minnesota Press: Minneapolis.

Klawans, H. L., Jr., and Garvin, J. S. (1969). Treatment of Parkinsonism with L-dopa. Dis. nerv. Syst., 30, 737-746.

McDowell, F., Lee, J. E., Swift, T., Sweet, R. D., Ogsbury, J. S., and Kessler, J. T. (1970). Treatment of Parkinson's Syndrome with L-dihydroxyphenylalanine (levodopa). Ann. int. Med., 72, 29-35.

Mawdsley, C. (1970). Treatment of Parkinsonism with Laevo-dopa. Brit. med. J., 1, 331-337. 
Milner, B., and Teuber, H. L. (1968). Alternation of perception and memory in man: reflections on method. In Analysis of Behavioral Change. Edited by L. Weiskrantz, pp. 268-375. Harper and Row: New York.

Mindham, R. H. S. (1970). Psychiatric symptoms in parkinsonism. J. Neurol. Neurosurg. Psychiat., 33, 188-191.

Satz, P., and Mogel, S. (1962). An abbreviation of the W.A.I.S. for clinical use. J. clin. Psychol., 18, 77-79.

Seashore, C. E., Lewis, D., and Saetveit, J. G. (1960). Manual of Instructions and Interpretations for the Seashore Measures of Musical Talents (1960) revision. Psychological Corp: New York.

Spreen, O., and Benton, A. L. (1963). Sentence Repetition Test. Neuropsychology Laboratory, Department of Psychology: University of Victoria.

Talland, G. A. (1962). Cognitive function in Parkinson's disease. J. nerv. ment. Dis., 135, 196-205.

Thorndike, E. L., and Lorge, I. (1944). The Teacher's Word Book of 30,000 Words. Teachers College, Columbia University: New York.
Treciokas, L., Markham, C. H., and Ansel, R. (1970). One to two years' treatment of Parkinson's disease with $\mathbb{D}$ levodopa. (Submitted to Calif. Med.)

Warburton, J. W. (1967a). Depressive symptoms in Parkinson patients referred for thalamotomy. J. Neurol. Neurosurg. Psychiat., 30, 368-370.

Warburton, J. W. (1967b). Memory disturbance and the Parkinson syndrome. Brit. J. med. Psychol., 40, 169-171.

Wechsler, D. (1955). Wechsler Adult Intelligence Scale: Manual. Psychological Corp: New York.

Williams, Moyra (1968). The measurement of memory in clinical practice. Brit. J. soc. clin. Psychol., 7, 19-34.

Wycis, H. T., Cunningham, W., Kellett, G., and Spiegel, E. A. (1970). L-dopa in the treatment of post-surgical Parkinson patients. J. Neurosurg., 32, 281-285.

Yahr, M. D., Duvoisin, R. C., Schear, M. J., Barrett, R. E., and Hoehn, M. M. (1969). Treatment of Parkinsonism with $\varrho$ Levodopa. Arch. Neurol. (Chic.), 21, 343-354. 